\title{
Robust global sensitivity analysis of a river management model to assess nonlinear and interaction effects
}

\author{
L. J. M. Peeters ${ }^{1}$, G. M. Podger ${ }^{2}$, T. Smith ${ }^{2}$, T. Pickett ${ }^{3}$, R. H. Bark ${ }^{4}$, and S. M. Cuddy ${ }^{2}$ \\ ${ }^{1}$ CSIRO Land and Water, Water for a Healthy Country Flagship, Adelaide, Australia \\ ${ }^{2}$ CSIRO Land and Water, Water for a Healthy Country Flagship, Canberra, Australia \\ ${ }^{3}$ CSIRO Land and Water, Water for a Healthy Country Flagship, Brisbane, Australia \\ ${ }^{4}$ CSIRO Ecosystem Sciences, Water for a Healthy Country Flagship, Brisbane, Australia
}

Correspondence to: L. J. M. Peeters (luk.peeters@csiro.au)

Received: 19 February 2014 - Published in Hydrol. Earth Syst. Sci. Discuss.: 25 March 2014

Revised: 1 August 2014 - Accepted: 1 September 2014 - Published: 29 September 2014

\begin{abstract}
The simulation of routing and distribution of water through a regulated river system with a river management model will quickly result in complex and nonlinear model behaviour. A robust sensitivity analysis increases the transparency of the model and provides both the modeller and the system manager with a better understanding and insight on how the model simulates reality and management operations.

In this study, a robust, density-based sensitivity analysis, developed by Plischke et al. (2013), is applied to an eWater Source river management model. This sensitivity analysis methodology is extended to not only account for main effects but also for interaction effects. The combination of sensitivity indices and scatter plots enables the identification of major linear effects as well as subtle minor and nonlinear effects.

The case study is an idealized river management model representing typical conditions of the southern MurrayDarling Basin in Australia for which the sensitivity of a variety of model outcomes to variations in the driving forces, inflow to the system, rainfall and potential evapotranspiration, is examined. The model outcomes are most sensitive to the inflow to the system, but the sensitivity analysis identified minor effects of potential evapotranspiration and nonlinear interaction effects between inflow and potential evapotranspiration.
\end{abstract}

\section{Introduction}

Water managers rely heavily on models to predict future water availability, optimize water use and evaluate water management strategies in order to find a balance between environmental, social and economic demands on the system. It is therefore crucial to be aware of the ability of a model to capture the dynamics of the hydrological cycle relevant to the water management question. In recent decades, addressing this issue has been the focus of much research in hydrological model calibration and predictive uncertainty analysis (Gupta et al., 2012).

For a modeller, to arrive at a "well"-calibrated model or to produce sensible and robust prediction intervals, it is essential to have a thorough understanding of how the hydrological system works and how this system is represented in the model - how a variation in parameters, boundary conditions or driving forces will affect the prediction of interest. The knowledge gained from such sensitivity analysis is not only of relevance during model development, it also provides added value to the model as it can focus management and monitoring to those aspects of the system and model that are most important to the management of water resources (Saltelli et al., 2008). Additionally, discussing model sensitivities with stakeholders will remove the notion of the model being a "black box" and can provide stakeholders with a better appreciation of the accuracy of the model, which has proven to be a key aspect of adoption of model results by management (Patt, 2009; Bark et al., 2013).

River management models such as eWater Source (Welsh et al., 2013) are increasingly used, especially in Australia, 
in the development of basin-wide water allocation plans. As these plans directly affect the livelihood of people and the health of ecosystems, it is essential that the models underpinning these plans have wide support and are robust. It is therefore essential that practitioners have a set of tools for sensitivity analysis available, tailored to the needs of water allocation modelling. The most straightforward sensitivity analysis technique is One-At-a-Time (OAT) sensitivity analysis in which one model aspect is changed while the others are fixed. The sensitivity of the model output to variation of the tested parameter is proportional to the gradient of the response surface. This is formalized in gradient-based calibration routines, such as Levenberg-Marquardt optimization. Examples of such OAT sensitivity analysis are Doherty and Hunt (2009), Foglia et al. (2009), Castaings et al. (2009) and Peeters et al. (2011). This methodology is attractive as it requires a very limited number of model runs, about two or three model runs per parameter evaluated, and, as long as the model behaves linearly, parameter interaction effects can be explored (Hill and Tiedeman, 2007). Saltelli and Annoni (2010) highlight that OAT sensitivity analysis only provides reliable and robust results if it can be shown that the model behaviour is linear. This condition is seldom satisfied for hydrological models or even known before a sensitivity analysis. The Elementary Effects method (Campolongo et al., 2007) is more robust against nonlinearity in the model behaviour, whilst still being frugal in the number of model runs.

Global sensitivity analysis techniques however do not require the model behaviour to be linear (Saltelli et al., 2008). The most straightforward global sensitivity analysis is either random or density-based sampling of parameter space and visualizing scatter plots of the parameter value against the prediction of interest (Wagener and Kollat, 2007; Peeters et al., 2013). Variance-based methods, such as Sobol' sensitivity analysis (Saltelli and Annoni, 2010; Nossent et al., 2011), use a scheme of structured resampling of a random base sampling to decompose the variance of the metric of interest into the main effects of a parameter and interaction effects of other parameters.

The main drawback of variance-based methods is that it assumes that the entire effect of a parameter can be summarized by the variance (Borgonovo, 2007; Borgonovo et al., 2011). Variance-based sensitivity indices will therefore be less reliable if the response to a parameter has a skewed or multi-modal distribution. Density-based sensitivity analysis techniques attempt to account for this by incorporating the entire distribution of the response of a prediction of interest in the metric in a way that does not require any assumptions on the shape of the distribution. The methodology suggested by Plischke et al. (2013) implements such a density-based sensitivity analysis technique which is independent of the parameter sampling scheme. This has the added benefit that as no model runs need to be devoted to the resampling of a base sampling, more computing resources can be directed to exploration of parameter space.
The goal of this study is to apply a density-based sensitivity analysis in a river management modelling context to assess its capability to identify and quantify nonlinear effects and to extend the methodology to account for interaction effects. An idealized, hypothetical river management model implemented in the eWater Source platform (Welsh et al., 2013) serves as testing platform to assess the ability of the sensitivity analysis methodology to quantify the influence of a small number of forcing variables upon a variety of model outcomes.

The next section presents the theoretical background and numerical implementation of the Plischke et al. (2013) global sensitivity analysis method. The river management model is briefly introduced before presenting the results of the sensitivity analysis and summarizing the findings in the discussion and conclusion sections.

\section{Methods}

The sensitivity analysis introduced in Plischke et al. (2013) provides a robust, global density-based sensitivity analysis, independent of sampling strategy. This section provides a short summary of this methodology. For a detailed overview the interested reader is referred to Plischke et al. (2013).

Consider $X$ and $Y$ the set of variables that comprise the input and output respectively of a river system model. Fixing $X$ to a single realization, the parameter combination $x$, results in a conditional cumulative distribution of $Y$ equal to $F_{Y \mid X=x}(y)$ and an equivalent density function $f_{Y \mid X=x}(y)$. The importance of fixing $X$ to $x$ can be quantified by the separation between the unconditional $F_{Y}(y)$ and the conditional $F_{Y \mid X=x}(y)$ or, similarly, the separation between $f_{Y}(y)$ and $f_{Y \mid X=x}(y)$. Using the L1-norm, the separation between the two density functions can be written as

$$
s(x)=\int_{Y}\left|f_{Y}(y)-f_{Y \mid X=x}(y)\right| \mathrm{d} y .
$$

The importance of factor $X$ on outcome $Y$ can then be defined as

$$
\begin{aligned}
\delta(Y, X) & =\frac{1}{2} \mathrm{E}[s(X)] \\
& =\frac{1}{2} \int_{X} f_{X}(x) \int_{Y}\left|f_{Y}(y)-f_{Y \mid X=x}(y)\right| \mathrm{d} y \mathrm{~d} x .
\end{aligned}
$$

The sensitivity index $\delta(X, Y)$ varies between 0 and 1 and it can be shown that this index is zero when $X$ and $Y$ are completely independent (Plischke et al., 2013).

To compute $\delta(X, Y)$ the integrals in Eq. (2) need to be approximated numerically. This can be achieved by taking $n$ samples of the parameter space $X$ and computing the corresponding values for $Y$. The method does not impose any restrictions on the sampling strategy of the parameter space. 


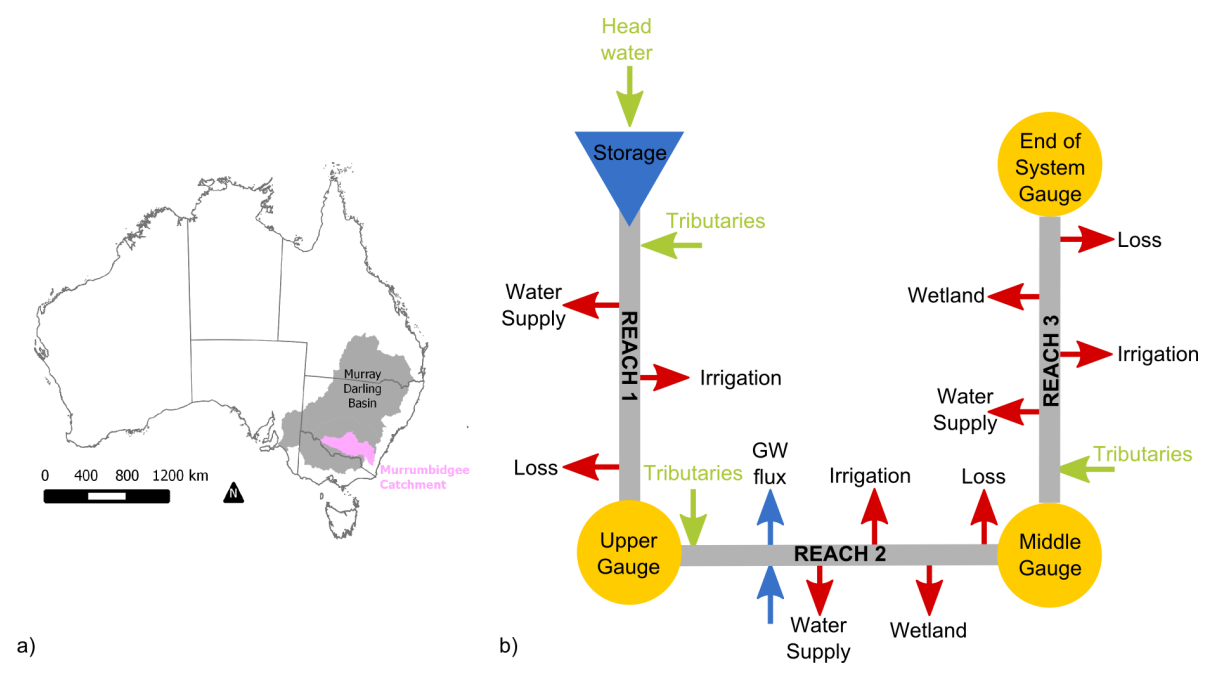

Figure 1. (a) Map showing the extent (indicated by pink shading) of the idealized river system model within the Murray-Darling Basin and (b) schematic structure of the river management model.

This implies that the methodology can be applied with random sampling, quasi-random sampling (e.g. Latin Hypercube Sampling or Sobol' sequences) or Markov chain Monte Carlo simulation.

The resulting data set is partitioned into $M$ classes $C_{m}$ with $m=1, \ldots, M$. For each class $C_{m}$, the density function can be approximated with a kernel smoothing function with kernel $K($.$) and bandwidth \alpha$ (Devroye and Gyorfi, 1985):

$$
\begin{aligned}
& \hat{f}_{Y}(y)=\frac{1}{n} \sum_{i=1}^{n} \frac{1}{\alpha} K\left(\frac{y-y_{i}}{\alpha}\right) \\
& \hat{f}_{Y \mid C_{m}}(y)=\frac{1}{n_{m}} \sum_{i: x_{i} \in C_{m}}^{n_{m}} \frac{1}{\alpha_{m}} K\left(\frac{y-y_{i}}{\alpha_{m}}\right),
\end{aligned}
$$

where $n_{m}$ is the number of samples in class $C_{m}$ and $\alpha_{m}$ the corresponding bandwidth for the kernel smoothing function.

The next step is to approximate the L1-norm between the two distributions for each class. Using a predefined number of quadrature points $\left\{\tilde{y}_{j}, j=1, \ldots, l\right\}$, the separation can be computed as

$s_{m, j}=\hat{f}_{Y}\left(\tilde{y}_{j}\right)-\hat{f}_{Y \mid C_{m}}\left(\tilde{y}_{j}\right)$

$\hat{S}_{m}=\frac{1}{2} \sum_{j=1}^{l-1}\left(\left|s_{m, j+1}\right|+\left|s_{m, j}\right|\right)\left(\tilde{y}_{j+1}-\tilde{y}_{j}\right)$.

The sensitivity index $\delta$ can then be approximated by

$\hat{\delta}=\frac{1}{2 n} \sum_{m=1}^{M} n_{m} \hat{S}_{m}$

To avoid bias in the sensitivity index and to assess the robustness of the sensitivity index estimate, it is recommended to perform a bootstrap of the sensitivity index (Efron, 1977) and to adjust $\hat{\delta}$ with the mean of the bootstrap $\bar{\delta}^{*}$ :

$\hat{\hat{\delta}}=2 \hat{\delta}-\bar{\delta}^{*}$.

$\hat{\hat{\delta}}$ provides the sensitivity index of the main effect of a variable. Plischke et al. (2013) however does not provide a method to explore second-order effects, i.e. the interaction between two variables. To estimate second-order effects between variables $X_{1}$ and $X_{2}$, the samples are subdivided into $n$ groups of equal intervals for $X_{1}$. The sensitivity index $\hat{\delta}$ for $X_{2}, \hat{\delta}_{X_{2}}$, is computed for each interval. If there is no interaction effect between $X_{1}$ and $X_{2}$, then $\hat{\delta}_{X_{2}}$ will not vary with the level of $X_{1}$. To quantify this, the variance of $\hat{\delta}_{X_{2}}$ is computed over all $n$ levels of $X_{1}$. Small variances indicate small interaction effects and vice versa.

\section{Model description and setup}

The case study is a hypothetical river system model (Fig. 1), based on a simplified version of the Murrumbidgee River model in New South Wales, Australia (Dutta et al., 2012; Podger et al., 2014). Using the full version of the Murrumbidgee River model was not warranted, not only because of the complexity of the system and the management rules, but, more importantly, because of legal issues with regard to model licensing and confidentiality. The idealized, hypothetical model retains most of the relevant complexity practitioners encounter when creating water allocation models, which is more than sufficient to illustrate the sensitivity analysis methodology.

In the model, water is routed from a storage reservoir through three river reaches. Routing starts in reach 1 at the storage reservoir with hydropower generators that receive water from a single tributary inflow. In reach 1 , water is taken 
Table 1. Output variables of the Source river system model.

\begin{tabular}{|c|c|c|}
\hline Name & Description & Units \\
\hline UpperFlow & Flow rate at the gauge at the end of the first reach & $\mathrm{m}^{3} \mathrm{~s}^{-1}$ \\
\hline MiddleFlow & Flow rate at the gauge at the end of the middle reach & $\mathrm{m}^{3} \mathrm{~s}^{-1}$ \\
\hline EndFlow & Flow rate at the gauge at the end of the final reach & $\mathrm{m}^{3} \mathrm{~s}^{-1}$ \\
\hline \$AlgalBloom & $\begin{array}{l}\text { Monetary value generated by recreation as function of the } \\
\text { risk of algal blooms }\end{array}$ & $10^{6}$ AUD \\
\hline \$Stor & Monetary value generated by recreation on storages & $10^{6}$ AUD \\
\hline \$TotalAg & Monetary value generated by irrigated agriculture & $10^{6}$ AUD \\
\hline Hydropower & Electricity generated from the storage reservoir & $\mathrm{kWh}$ \\
\hline GenSec & $\begin{array}{l}\text { Percentage of time general security licences receive their } \\
\text { full entitlement }\end{array}$ & $\%$ \\
\hline
\end{tabular}

from the system for town water supply and irrigation and water is received from unregulated rain-fed tributaries. From the Upper Gauge at the end of reach 1, water is routed through reach 2 . In this reach, interaction with groundwater is taken into account by an exchange flux. As in reach 1 , water is received from unregulated, rain-fed tributaries and water is taken out for irrigation and town water supply. In addition to these offtake, water is diverted into an off-river wetland system. Reach 3 starts at the middle gauge and is similar to reach 2. It also has offtake for town water supply, irrigation and off-river wetlands and receives inflow from rainfed tributaries. Groundwater-surface water interaction is not taken into account in this reach. Each reach has a term representing unaccounted losses. The loss relationships are taken from the more complex model. The total travel time from headwater to end-of-system is 18 days ( 3 days for reach 1, 6 days for reach 2 and 9 days for reach 3 ). These values, together with the other parameters influencing routing of water are also taken and aggregated from the more complex model.

Daily time series of rainfall and evaporation from 1895 to 2006 are obtained from SILO (http://www.longpaddock. qld.gov.au/silo/) for sites representative of each of the three reaches. These time series are used to simulate inflow from tributaries and compute irrigation demand. Inflow into the main storage in the model is taken from daily gauged data from 1895 to 2006.

The town water demands are based on a fixed annual pattern $\left(8.8,3.0\right.$ and $1.2 \times 10^{6} \mathrm{~m}^{3}$ year $^{-1}$ for reaches 1,2 and 3 respectively). Irrigation demands are based on a reach-based aggregation of irrigation use as well as rationalizing of crop types. There are environmental demands for the wetlands in reach 2 and 3, which are designed to establish and maintain favourable habitat conditions for indigenous fauna and flora (Janssen, 2012).

Two aspects of water management are considered: $347 \mathrm{~m}^{3} \mathrm{~s}^{-1}$ order constraint on storage releases, i.e. the maximum flow that can be requested by water users in the system of the storage, and an annual allocation system. The allocation system comprises high and general security order debit annual accounting schemes. Water is first allocated from the storage to high security entitlement holders and only once these are fulfilled is water allocated to general security entitlement holders. The start of the water year is 1 July with allocations updated continuously throughout the year, where these include allowances for minimum tributary inflows and delivery losses. At the end of the water year accounts are reset to zero. Licence entitlements were aggregated on a reach basis. Two socio-economic indicators have been included to indicate the impacts of storage volumes on recreational usage and mid-river flows on algal blooms and the associated impact on recreational usage. There are three storage volume categories $(<10,<50$ and $>50 \%)$ for recreational usage based on visitor numbers. Recreational benefits are calculated for periods of time the model is at each threshold, using the Crase and Gillespie (2008) 100000 visitor estimate to Lake Hume. Estimates of visitor numbers at high and low storage volumes are based on this estimate and the actual Tourism Research Australia (TRA) average, low and high visitor numbers in the Murrumbidgee catchment in the period 2003-2010 (DRET, 2010). Benefit transfer recreation values are taken from the same study (updated to 2012 Australian dollars (AUD) using the Australian Consumer Price Index, CPI). There are three risk of algal bloom categories (no bloom, alert and bloom) - no bloom occurs if there is a flow of at least $11.6 \mathrm{~m}^{3} \mathrm{~s}^{-1}$ in the previous 7 days and alert if this flow occurs within the previous 14 days; if flow does not exceed $11.6 \mathrm{~m}^{3} \mathrm{~s}^{-1}$ in the previous 14 days, algal bloom is simulated to occur. Australian dollars have been associated with loss of amenity in the weeks when there is an alert or bloom using the thresholds, estimated visitor numbers using TRA data and high and low estimates of river recreation based on survey data (DRET, 2010), and benefit transfer of general recreation benefits from Morrison and Hatton MacDonald (2010) (2010 AUD values are updated to 2012 AUD using the CPI and where the full value is used for no bloom, a proportion based on Crase and Gillespie (2008) for an alert and 0 AUD for a bloom). 

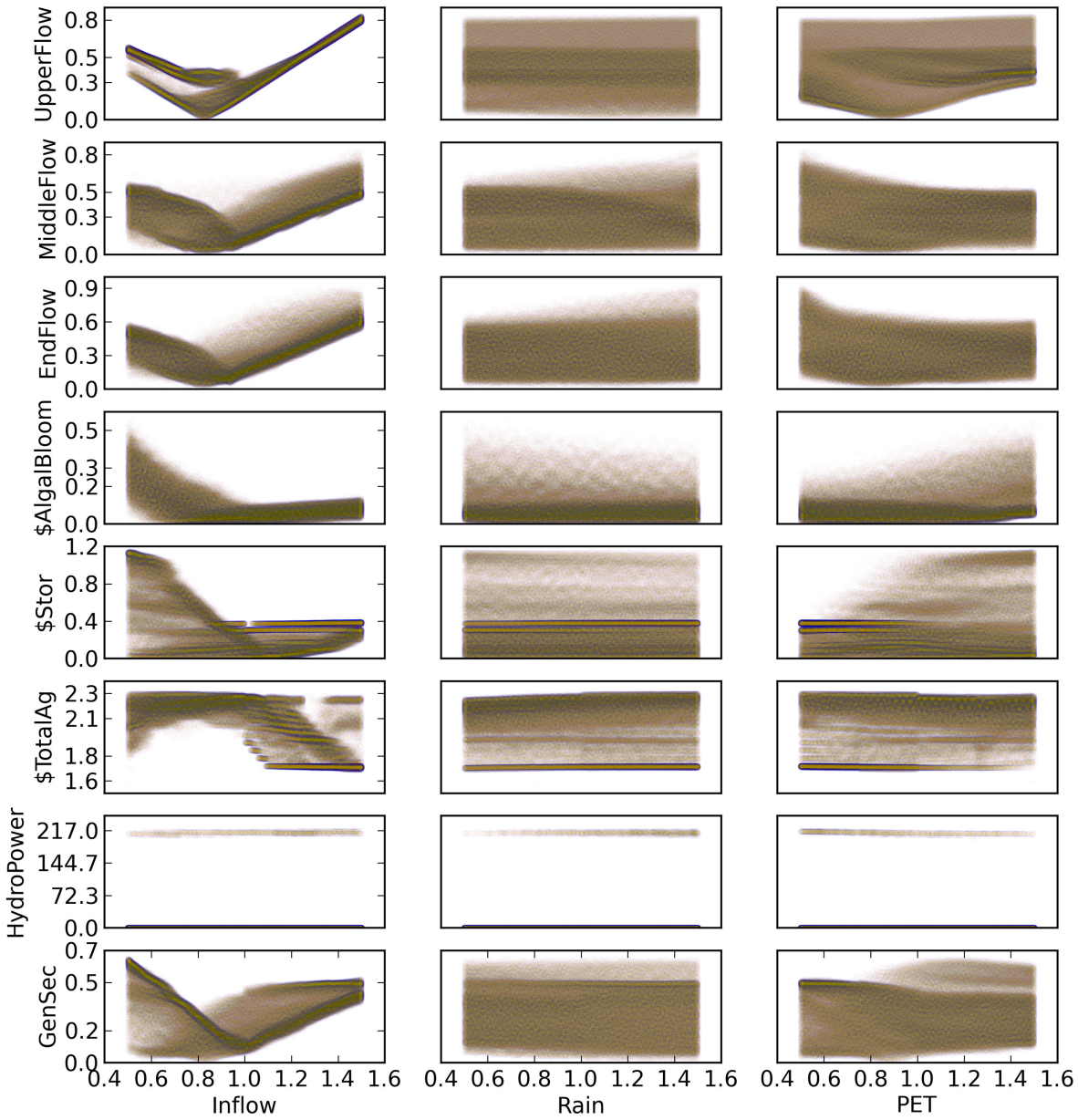

Figure 2. Scatter plots of $\hat{M}$, the difference between kernel density estimates for each simulation and the kernel density estimate of the reference simulation for all forcing data and model output variables for the eWater Source hypothetical river management model.

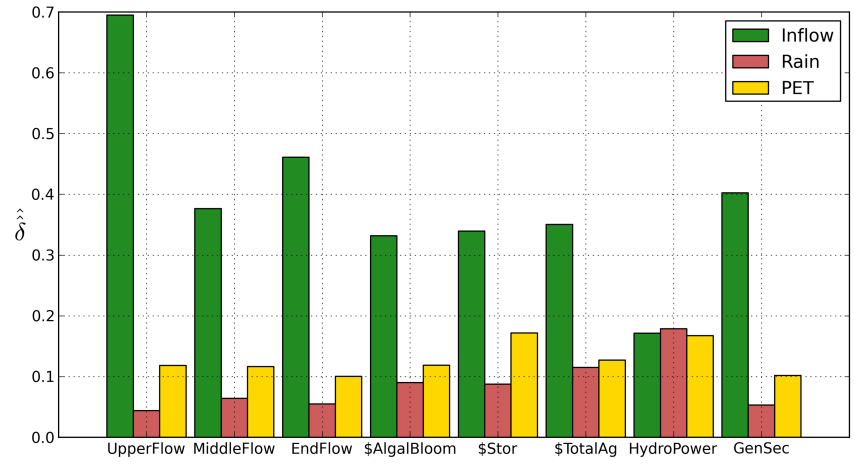

Figure 3. Sensitivity indices, $\hat{\hat{\delta}}$, for all forcing data and model output variables for the eWater Source hypothetical river management model.

\section{Results}

In the sensitivity analysis, the three main forcing variables are considered: the system inflow (Inflow), the precipitation (Rain) and the potential evapotranspiration (PET). The latter two affect the inflow into the reaches and the irrigation demand. Inspired by the work of Leblanc et al. (2012), the forcing variables are changed through a multiplier to the corresponding input time series with the range of the multiplier for each variable between 0.5 and 1.5 . This range encompasses both historical variation in hydrological input and output, as well as the expected change under various climate change models and scenarios. While elaborate schemes are available to perturb hydrological time series, this is not warranted in this study as the focus is on metrics that integrate the entire flow time series. As such, the emphasis of this research is on changes in total flow in or out of the model, rather than in changes of the timing of flow.

Using Sobol' sequences (Sobol, 1976), 100000 quasirandom samples of the three input variables are generated. For each of these samples a range of output time series is 

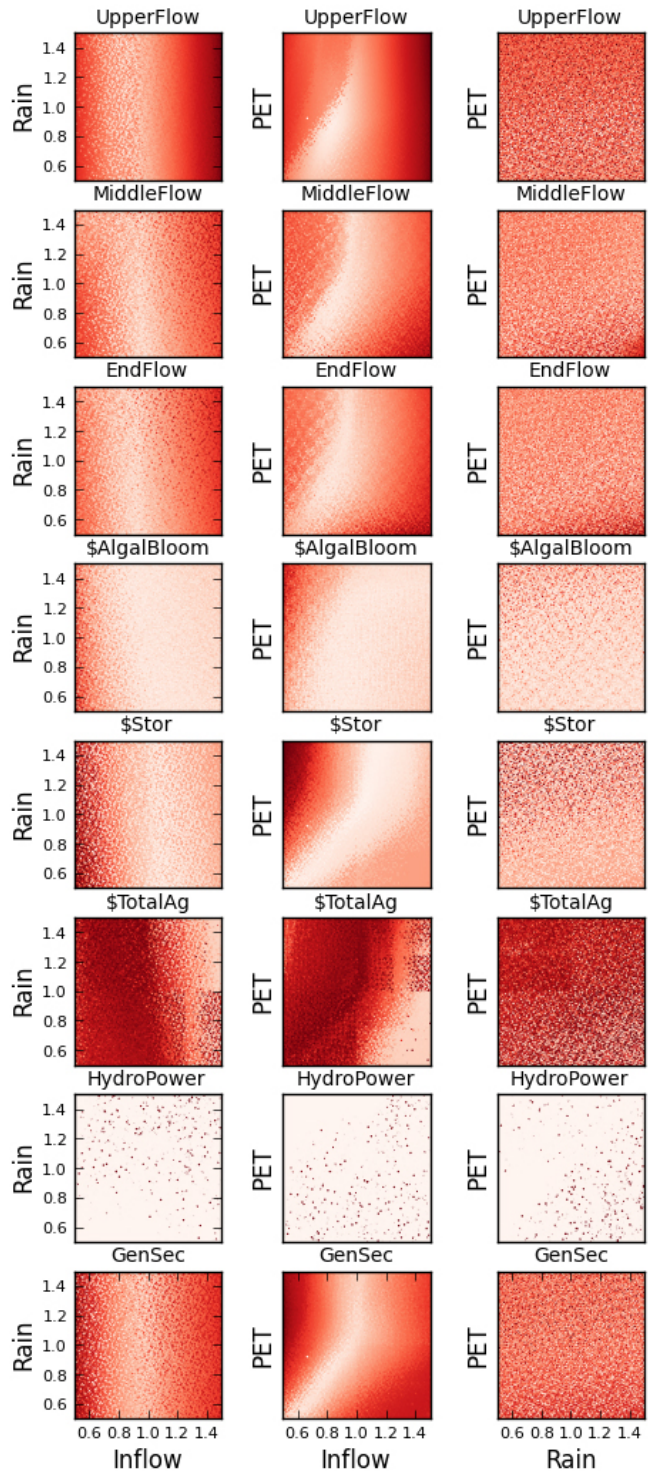

Figure 4. Scatter plots of interaction of the driving forces. The intensity of the colour scale is proportional to the model outcome value, where dark red indicates high values and light red indicates low values.

calculated (Pickett et al., 2013). Table 1 lists the names of the output series and a short description.

Each of the output variables in Table 1 is a daily time series. The metric for the sensitivity for different forcing data $(\hat{M})$ is the difference between the kernel density estimate of the daily times series of a randomly selected reference simulation $\left(\hat{f}_{\text {Yref }}(y)\right)$ and the kernel density estimate of the daily time series for the changed forcing data $\left(\hat{f}_{\text {Ysim }}(y)\right)$ :

$\hat{f}_{\text {Yref }}(y)=\frac{1}{n} \sum_{j=1}^{n} \frac{1}{\alpha} K\left(\frac{y_{\text {ref }}-y_{\text {ref }, i}}{\alpha}\right)$

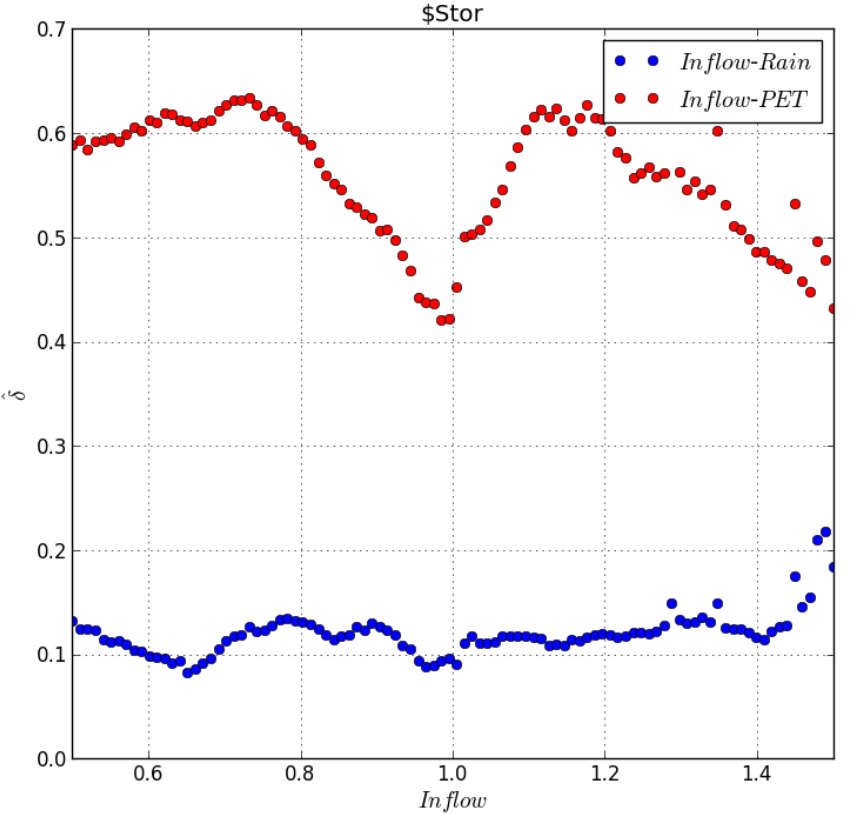

Figure 5. Sensitivity index $\hat{\delta}$ of the effect of Rain (blue) and PET (red) on \$Stor for 100 equal intervals of Inflow.

$$
\begin{aligned}
\hat{f}_{\mathrm{Ysim}}(y) & =\frac{1}{n} \sum_{j=1}^{n} \frac{1}{\alpha} K\left(\frac{y_{\mathrm{sim}}-y_{\mathrm{sim}, i}}{\alpha}\right) \\
d_{j} & =\hat{f}_{\mathrm{Yref}}\left(\tilde{y}_{j}\right)-\hat{f}_{\mathrm{Ysim}}\left(\tilde{y}_{j}\right) \\
\hat{M} & =\frac{1}{2} \sum_{j=1}^{l-1}\left(d_{j+1}+d_{j}\right)\left(\left|\tilde{y}_{j+1}-\tilde{y}_{j}\right|\right)
\end{aligned}
$$

The choice of this metric is motivated by the fact that, since the case study is an idealized, hypothetical model, it is not possible to directly compare the results with observations. In addition to this, and more importantly, the variety of model outcomes examined in this study are more than likely to be affected by different aspects of the hydrograph. Similar to choosing an objective function in traditional calibration or a likelihood function in uncertainty analysis, such metric needs to be tailored to be able to capture the relevant aspects of the hydrograph. Choosing an ill-suited metric can have huge consequences for the sensitivity analysis, calibration or uncertainty analysis, as pointed out in Montanari and Koutsoyiannis (2012) and Nearing (2014). The metric presented in Eq. (7) is designed to provide an as general and robust as possible measure of the difference between two time series as not to bias the interpretation of the sensitivity analysis.

\subsection{Main effects}

Figure 2 shows the scatter plots of sensitivity metric $\hat{M}$ for all combinations of forcing data and output variables. It is clear that the dominant influencing driving variable is Inflow, as 


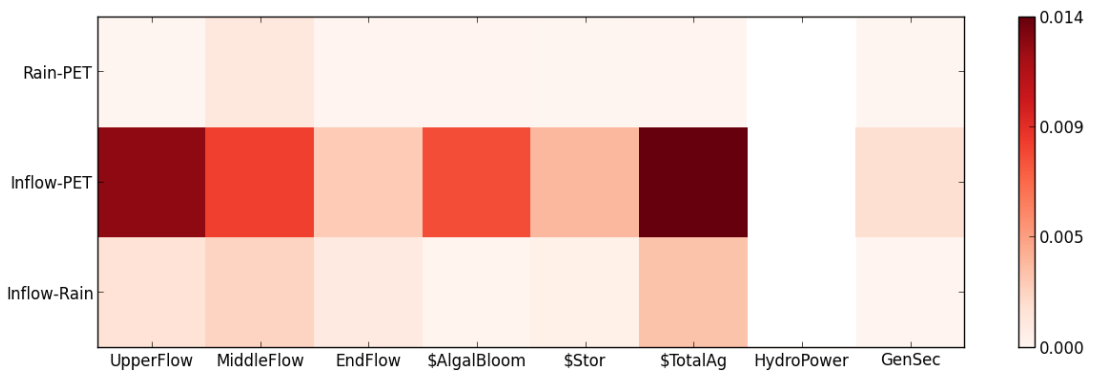

Figure 6. $\operatorname{Var}\left(\hat{\delta}_{X 1-X 2}\right)$ for all combinations of driving forces for all model outcomes. High values indicate potential interaction between $X 1$ and $X 2$. The values for Hydropower are omitted in order not to distort the visualization.

a strong response is noticeable for variations in this driving variable for all output variables with the exception of HydroPower. The effects of "Rain" and "PET" are less pronounced. A very striking feature are the many nonlinearities in the response surface of the hypothetical model. This is mostly due to a number of threshold values used in the management rules of the river management system. For instance, generation of hydro-power is only possible when the storage level in the dam exceeds a predefined threshold related to the height of the water intake point for the turbines.

Figure 3 shows a barplot of the sensitivity indices $\hat{\hat{\delta}}$ for all main effects. These indices confirm the dominant influence of Inflow on most output variables. They provide a relative ranking of the influence of the input variable Inflow on the various output variables. MiddleFlow, EndFlow and GenSec respond to a similar degree to changes in Inflow and the same is true for the output variables related to monetary value (\$AlgalBloom, \$Stor and \$TotalAg). HydroPower is least influenced by Inflow, which, from Fig. 2, is clearly related to the threshold-induced nonlinear behaviour.

The methodology is also able to quantify the often small and nonlinear effects of the other forcing variables. This is especially noticeable for PET. There is a clear but highly nonlinear effect of PET on $\$$ Stor, which is reflected in a higher $\hat{\hat{\delta}}$. The output variable HydroPower has a bimodal distribution where the majority of simulations have an $\hat{M}$ close to zero. Nevertheless, the global sensitivity method is able to distinguish and quantify the subtle trends in the non-zero values for the different input variables.

\subsection{Interaction effects}

The previous section established the importance of Inflow as the main driving variable. It is however from both a management and modelling perspective interesting to have an understanding of how the interaction between variables affects the model outcome.

Figure 4 shows plots with the factor values on the $x$ - and $y$-axis, with a colour scale to visualize $\hat{M}$ for the three combinations of interaction of the driving forces (Inflow-Rain, Inflow-PET and Rain-PET) for all eight model outcomes.
The first column shows that the effect of Inflow on most of the model outputs does not vary with the value of Rain. There is however a clear interaction between Inflow and PET for most of the model outputs; while the Inflow response is the dominant feature in the plots, the shape of this response depends on the value of PET. HydroPower is a noted exception as it displays very little structure in the scatter plots. This is because hydropower is generated by release of water from the reservoir in function of the demand and the water level in the reservoir. These management rules create a buffer to immediate impact from rainfall and inflow and also result in nonlinear, threshold related behaviour.

Very little structure is noticeable in the third column of Fig. 4, which shows the interaction between Rain and PET, reflecting the limited influence both driving forces have as a main effect.

To quantify the interaction effect for each interaction combination in Fig. 4, the variance of the $\hat{\delta}$ of the variable on the $y$-axis is computed for 100 equal intervals of the variable on the $x$-axis. By using Sobol' sequences to generate the 100000 samples of the parameter space, each equal interval of the $x$-axis variable has approximately 1000 samples to compute the $\hat{\delta}$.

Figure 5 illustrates this for the interaction effects of Inflow, Rain and PET on \$Stor. The sensitivity index values for Rain are low and hardly vary for different levels of Inflow, which is an indication of very limited interaction between Rain and Inflow, as confirmed by the scatter plot (Fig. 4). The $\hat{\delta}$ values for PET vary markedly with the level of Inflow. This sensitivity index reaches a minimum for Inflow values close to 1 , while reaching peaks close to values of 0.75 and 1.1. This is reflected in the variance of the $\hat{\delta}$ values which is $4.5 \times 10^{-4}$ for the Inflow-Rain couple and $3.5 \times 10^{-3}$ for Inflow-PET. Figure 6 shows the variance of the sensitivity indices for all interaction pairs for all model outcomes. The values for Hydropower are much higher than for the other model outcomes due to the nonlinear behaviour. They were omitted from Fig. 6 as they distorted the visualization.

The most dominant interaction effects are between Inflow and PET for \$TotalAg and UpperFlow, followed by \$AlgalBloom, \$Stor and MiddleFlow. 


\section{Discussion}

The sensitivity analysis of the hypothetical river management model highlights inflow as a crucial variable of the model and how this affects the economic, environmental and sociological functions of the river. This emphasizes the importance of an accurate characterization of the flow rates of upstream areas when modelling flow routing in regulated systems comparable to the case study, i.e. the regulated river systems of the Murray-Darling Basin in Australia. An accurate characterization of flow rates not only entails maintaining a dense river gauge network, it also means adequately describing the measurement uncertainty in the flow rates, not in the least the uncertainty introduced by the rating curve that describes the stage-discharge relationship (Tomkins, 2012). The work of Hughes et al. (2014) illustrates this as they identify the inflow from ungauged catchment as crucial in the calibration of river management models.

Direct precipitation in the storage, wetlands and irrigation areas has a very minor influence on the model outcomes. This is mostly due to the small volume of rainfall $\left(0.633 \mathrm{~km}^{3} \mathrm{yr}^{-1}\right)$ compared to the inflow volume $\left(4.4 \mathrm{~km}^{3} \mathrm{yr}^{-1}\right)$ and the correlation between the inflow volume and rainfall. Any effect of rainfall will therefore be dwarfed by the effect of inflow to the system. The interaction effect of Inflow and PET is mostly due to the feedback mechanism as irrigation requirements increase with increasing potential evapotranspiration.

Such parameter interaction is well known in other areas of hydrological modelling, such as in rainfall-runoff modelling (Gallagher and Doherty, 2007; Zhang et al., 2013; Peeters et al., 2013) and in groundwater modelling (Doherty and Hunt, 2009), although it has not received much attention in river system modelling. Letcher et al. (2007) discuss the importance of interacting effects in water allocation models, without however providing a rigorous quantitative framework to evaluate the effects.

The sensitivity analysis in this study was limited to multiplying factors on three driving forces. It would be very insightful to include other model parameters in the sensitivity analysis, especially those controlling storage volumes and irrigation requirements. Along the same lines, including the parameters of the management rules, e.g. rules on allocations, in the sensitivity analysis can yield additional understanding of the operational management of the river system, as shown by Micevski et al. (2011).

\section{Conclusions}

The density-based sensitivity analysis of Plischke et al. (2013) has been applied to a river management model representing an idealized regulated river system representative of the southern Murray-Darling Basin in Australia to iden- tify the main and interaction effects of three driving forces on several hydrological and socio-economic model outcomes.

The extended sensitivity analysis method presented in this paper provides a quantitative measure of sensitivity of the main and interaction effects and, through a combination with qualitative visual inspection of scatter plots, proved to be able to identify not only major effects but also subtle interactions, even in the presence of strong nonlinearities.

Due to the small dimensionality of the case study, it was possible to visualize all main effects and their interactions through scatter plots for all model outcomes. Although this will be challenging for higher-dimensional problems, the visual inspection of scatter plots is an invaluable complement to the sensitivity indices.

Understanding the dynamics of river system models is often not intuitive, especially in larger or basin-scale models (Johnston and Smakhtin, 2014). A robust and comprehensive sensitivity analysis is an invaluable step in model development to elucidate the often intricate interactions between driving forces, management rules and parameters. Increased understanding of the model will not only lead to improvements in calibration and prediction, it also has enormous potential in establishing the credibility and understanding of models.

Acknowledgements. The authors thank Russell Crosbie and Dave Penton for their constructive comments.

Edited by: H. Cloke

\section{References}

Bark, R., Peeters, L., Lester, R., Pollino, C., Crossman, N., and Kandulu, J.: Understanding the sources of uncertainty to reduce the risks of undesirable outcomes in large-scale freshwater ecosystem restoration projects: An example from the Murray-Darling Basin, Australia, Environ. Sci. Pol., 33, 97-108, 2013.

Borgonovo, E.: A new uncertainty importance measure, Reliability Eng. Syst. Safety, 92, 771-784, 2007.

Borgonovo, E., Castaings, W., and Tarantola, S.: Moment Independent Importance Measures: New Results and Analytical Test Cases, Risk Anal., 31, 404-428, 2011.

Campolongo, F., Cariboni, J., and Saltelli, A.: An effective screening design for sensitivity analysis of large models, Environ. Modell. Softw., 22, 1509-1518, 2007.

Castaings, W., Dartus, D., Le Dimet, F.-X., and Saulnier, G.-M.: Sensitivity analysis and parameter estimation for distributed hydrological modeling: potential of variational methods, Hydrol. Earth Syst. Sci., 13, 503-517, doi:10.5194/hess-13-503-2009, 2009.

Crase, L. and Gillespie, R.: The impact of water quality and water level on the recreation values of Lake Hume, Aust. J. Environ. Manage., 15, 21-29, 2008.

Devroye, L. and Gyorfi, L.: Nonparametric Density Estimation: The L1 View, John Wiley \& Sons, Ltd New York, NY., 1985. 
Doherty, J. and Hunt, R. J.: Two statistics for evaluating parameter identifiability and error reduction, J. Hydrol., 366, 119-127, 2009.

DRET: Destination visitor survey: strategic regional research report - New South Wales, Victoria and South Australia. Impact of the drought on tourism in the Murray River Region., Tech. rep., Department of Resources, Energy and Tourism, Tourism Research Australia, 57 pp., 2010.

Dutta, D., Hughes, J., Vaze, J., Kim, S., Yang, A., and Podger, G.: A daily river system model for the Murray-Darling Basin: development, testing and implementation, in: 34th Hydrology and Water Resources Symposium 2012, Sydney, 19-22 November 2012, 1057-1066, available at: http://www.hwrs2012.org.au/, 2012.

Efron, B.: Bootstrap methods: another look at the jackknife, The Annal. Stat., 7, 1-26, 1977.

Foglia, L., Hill, M. C., Mehl, S. W., and Burlando, P.: Sensitivity analysis, calibration, and testing of a distributed hydrological model using error-based weighting and one objective function, Water Resour. Res., 45, W06427, doi:10.1029/2008WR007255, 2009.

Gallagher, M. R. and Doherty, J.: Parameter interdependence and uncertainty induced by lumping in a hydrologic model, Water Resour. Res., 43, W05421, doi:10.1029/2006WR005347, 2007.

Gupta, H. V., Clark, M. P., Vrugt, J. A., Abramowitz, G., and Ye, M.: Towards a comprehensive assessment of model structural adequacy, Water Resour. Res., 48, W08301, doi:10.1029/2011WR011044, 2012.

Hill, M. C. and Tiedeman, C. R.: Effective groundwater model calibration, Wiley, 2007.

Hughes, J., Dutta, D., Vaze, J., Kim, S., and Podger, G.: An automated multi-step calibration procedure for a river system model, Environ. Modell. Softw., 51, 173-183, 2014.

Janssen, V.: Indirect Tracking of Drop Bears Using GNSS Technology, Aust. Geogr., 43, 445-452, doi:10.1080/00049182.2012.731307, 2012.

Johnston, R. and Smakhtin, V.: Hydrological Modeling of Large river Basins: How Much is Enough?, Water Resour. Manage., 28, 1-36, doi:10.1007/s11269-014-0637-8, 2014.

Leblanc, M., Tweed, S., Van Dijk, A., and Timbal, B.: A review of historic and future hydrological changes in the Murray-Darling Basin, Global Planet. Change, 80-81, 226-246, 2012.

Letcher, R. A., Croke, B. F. W., and Jakeman, A. J.: Integrated assessment modelling for water resource allocation and management: A generalised conceptual framework, Environ. Modell. Softw., 22, 733-742, 2007.

Micevski, T., Lerat, J., Kavetski, D., Thyer, M., and Kuczera, G.: Exploring the utility of multi-response calibration in river system modelling, 19th International Congress On Modelling and Simulation (modsim2011), 12-16 December 2011, Perth, Australia, 3889-3895, 2011.

Montanari, A. and Koutsoyiannis, D.: A blueprint for process-based modeling of uncertain hydrological systems, Water Resour. Res., 48, W09555, doi:10.1029/2011WR011412, 2012.

Morrison, M. and Hatton MacDonald, D.: Economic valuation of environmental benefits in the Murray-Darling Basin, Tech. rep., A report to the Murray Darling Basin Authority, 2010.

Nearing, G.: Comment on "A blueprint for process-based modeling of uncertain hydrological systems" by Monta- nari and Koutsoyiannis, Water Resour. Res., 50, 6260-6263, doi:10.1002/2013WR014812, 2014.

Nossent, J., Elsen, P., and Bauwens, W.: Sobol' sensitivity analysis of a complex environmental model, Environ. Modell. Softw., 26, 1515-1525, 2011.

Patt, A.: Uncertainties in environmental modelling and consequences for policy making, chap. Communicating uncertainty to policy makers, pp. 231-251, NATO science for peace and security series - C: Environmental Security, Springer, available at: http://www.pik-potsdam.de/news/public-events/archiv/alter-net/ former-ss/2009/14.09.2009/patt/literature/bavaye-book.pdf, 2009.

Peeters, L., Lerat, J., and Rassam, D.: Improving parameter estimation in transient groundwater models through temporal differencing, in: MODSIM 2011: Sustaining Our Future, 12-16 December 2011, Perth, Australia, p. 7, 2011

Peeters, L., Crosbie, R., Doble, R., and Van Dijk, A.: Conceptual evaluation of continental land-surface model behaviour, Environ. Modell. Softw., 43, 49-59, 2013.

Pickett, T., Smith, T., Bulluss, B., Penton, D., Peeters, L., Podger, G., and Cuddy, S.: Approaches to distributed execution of hydrologic models: methods for ensemble Monte Carlo risk modelling with and without workflows, in: MODSIM 2013 20th International Congress on Modelling and Simulation, 1-6 December 2013, Adelaide, Australia, p. 7, 2013.

Plischke, E., Borgonovo, E., and Smith, C. L.: Global sensitivity measures from given data, Eur. J. Operational Res., 226, 536550, 2013.

Podger, G., Cuddy, S., Peeters, L., Smith, T., Bark, R., and Black, D.: Risk management frameworks: supporting the next generation of Murray-Darling Basin water sharing plans, in: Evolving Water Resources Systems: Understanding, Predicting and Managing Water-Society Interactions, Proceedings of ICWRS2014, Bologna, Italy, June 2014 (IAHS Publ. 364, 2014, 452-457), 364, 452-457, 2014.

Saltelli, A. and Annoni, P.: How to avoid a perfunctory sensitivity analysis, Environ. Modell. Softw., 25, 1508-1517, 2010.

Saltelli, A., Ratto, M., Andres, T., Campolongo, F., Cariboni, J., Gatelli, D., Saisana, M., and Tarantola, S.: Global Sensitivity Analysis. The Primer, John Wiley \& Sons, Ltd, doi:10.1002/9780470725184, 2008.

Sobol, I.: Uniformly distributed sequences with an additional uniform property, USSR Comput. Mathem. Mathem. Phys., 16, 236-242, 1976.

Tomkins, K. M.: Uncertainty in streamflow rating curves: methods, controls and consequences, Hydrol. Process., 28, 464-481, doi:10.1002/hyp.9567, 2012.

Wagener, T. and Kollat, J.: Numerical and visual evaluation of hydrological and environmental models using the Monte Carlo analysis toolbox, Environ. Modell. Softw., 22, 1021-1033, 2007.

Welsh, W. D., Vaze, J., Dutta, D., Rassam, D., Rahman, J. M., Jolly, I. D., Wallbrink, P., Podger, G. M., Bethune, M., Hardy, M. J., Teng, J., and Lerat, J.: An integrated modelling framework for regulated river systems, Environ. Modell. Softw., 39, 81-102, 2013.

Zhang, C., Chu, J., and Fu, G.: Sobolś sensitivity analysis for a distributed hydrological model of Yichun River Basin, China, J. Hydrol., 480, 58-68, 2013. 